\title{
Subtle messaging changes could boost organ donor numbers
}

\author{
n Cite as: CMAJ 2021 May 10;193:E700-1. doi: 10.1503/cmaj.1095939
}

Posted on cmajnews.com on April 26, 2021

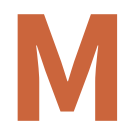

ost Canadians believe organ donation is the right thing to do, but motivating them to register as donors may require a particular turn of phrase, according to researchers from the University of British Columbia (UBC).

Many organ and tissue donor agencies advertise how few people are registered as donors, hoping to encourage registration by demonstrating need, said Rishad Habib, a PhD candidate in marketing and consumer studies at UBC. However, creating the perception that "nobody is doing something" can easily backfire. "You automatically reduce how important it is," Habib said.

Campaigns that emphasize broad social support for organ donation can also backfire by leading people to believe that others are already helping, diffusing any personal responsibility to register, Habib said.

In a series of studies published in the Journal of Consumer Psychology, Habib and colleagues found that combining these approaches motivated more people to register as donors than either strategy alone.

In the first study involving 546 people, researchers conducted a donor drive at a university student centre, rotating between a "low norm" message emphasizing how few people are registered as donors, a "high norm" message emphasizing that most people believe others should register as donors, and a combined message - " $90 \%$ of Canadians believe people should register as organ donors but only $20 \%$ are registered."

People were most likely to register as donors after reading the combined message (33\%) compared to the low norm message $(23 \%)$ or the high norm message (19\%).

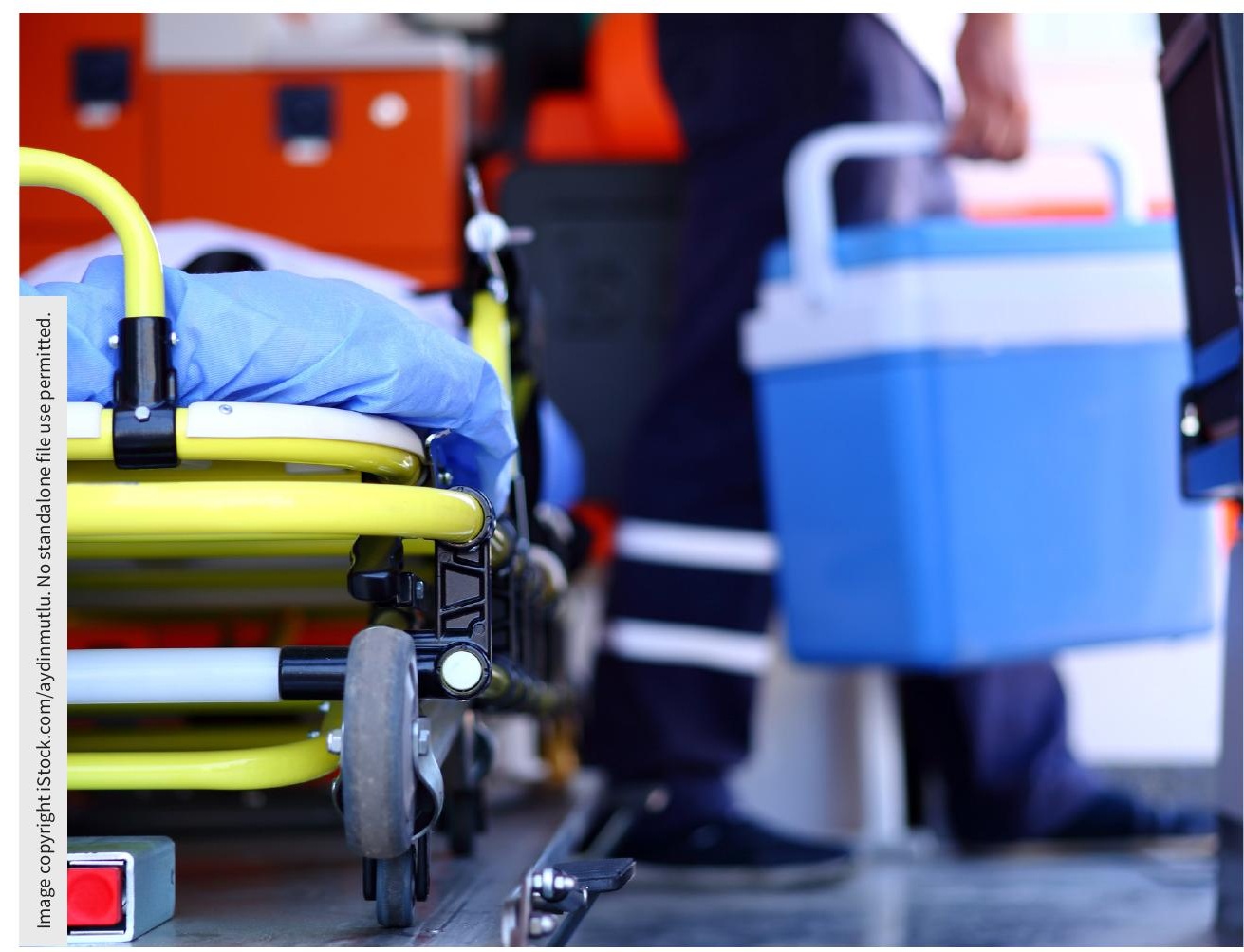

How transplant programs talk about organ donation affects registration.

In a second study of 404 Americans and a third study of 1183 Canadians, Habib and colleagues found that this combined approach also increased participants' feelings of personal responsibility, which, in turn, increased their intention to register as donors.

The findings come as Canada faces ongoing shortages of organs for transplant. Even before the COVID-19 pandemic, more than 4300 Canadians were waiting for organs. Fewer than a third of Canadians are registered as donors, and donor registration has dropped 39\% during the pandemic.

Habib and her colleagues noted that their findings could also improve health communication in other contexts "where there is a high degree of public support for positive action but low rates of behaviour change, such as blood donation, medication adherence... and preventive behaviours such as wearing masks."

Apathy remains a major barrier to donor registration, prompting calls for the wider adoption of "opt-out" donation systems to boost the supply of organs.

In January, Nova Scotia became the first North American jurisdiction to adopt an opt-out organ donation system. So far, only $1 \%$ of the population has declined to donate their organs after death. The policy change has not yet translated into more transplant operations, according to the Chronicle Herald. 
However, more hospital staff are requesting information about the transplant process.

Misinformation may pose another barrier to donor registration. Habib noted that many study participants expressed misconceptions about registering as an organ donor. Some believed that they wouldn't be able to change their decisions, while others worried "they wouldn't get the proper care if people knew their organs were going to be donated."

"That's not actually true. The doctors treating the patient don't know whether they're registered as an organ donor," said Habib. "There are a lot of misconceptions where I think doctors can help patients understand and have the correct information."

\section{Diana Duong, CMAJ}

Content licence: This is an Open Access article distributed in accordance with the terms of the Creative Commons Attribution (CC BY-NC-ND 4.0) licence, which permits use, distribution and reproduction in any medium, provided that the original publication is properly cited, the use is noncommercial (i.e., research or educational use), and no modifications or adaptations are made. See: https://creativecommons.org/ licenses/by-nc-nd/4.0/ 